\title{
PRINCIPAIS TIPOLOGIAS DE EXPLORAÇÕES AGRÍCOLAS NA UNIÃO EUROPEIA
}

RESUMO: Este trabalho tem como principal objetivo caracterizar e segmentar as explorações agrícolas dos vinte e oito Estados Membros da União Europeia. Para esse efeito, utilizam-se técnicas de análise de cluster de casos e de cluster de explorações. Foram obtidos quatro grupos de explorações nos vinte e oito Estados Membros da União Europeia. Os grupos de explorações distinguem-se pelas suas características estruturais, financeiras, orientação produtiva e importância dos subsídios recebidos da Política Agrícola Comum. Estes resultados sugerem a definição de uma Política Agrícola Comum diferenciada e adaptada aos quatro clusters existentes. Sugere-se ainda o desenvolvimento de tipologias de explorações na União Europeia com dados mais robustos de todas as regiões dos diferentes países, de forma a obter tipologias de todas as regiões europeias.

PALAVRAS-CHAVE: Análise de cluster; Análise multivariada; Estados Membros da União Europeia; Política Agrícola Comum; Tipificação das explorações agrícolas.

\section{MAIN T YPOLOGIES OF AGRICULTURAL EXPLOITATION IN THE EUROPEAN UNION}

ABSTRACT: Agricultural exploitation of the 28 member states of the European Union is characterized and analyzed. Cluster and exploitation analyses of cases are employed. Four exploitation groups within the 28 member states of the European Union were retrieved. Groups are distinguished by their structural, financial, productive orientation and importance of subsidies received from the Common Agricultural Policy. Results suggest a definition of a differentiated Common Agricultural Policy adapted to the four clusters. The development of exploitation typologies in the EU is suggested with more robust data from all the countries involved so that typologies for all the European regions would be obtained.

KEY WORDS: Cluster analysis; Multivariate analysis; Member states of the European Union; Common Agricultural Policy; Typifying agricultural exploitation. 


\section{INTRODUÇÃO}

Existe um vasto conjunto de literatura que caracteriza e segmenta as explorações agrícolas de diferentes zonas específicas da União Europeia (UE). Grande parte destes estudos procura compreender as mudanças estruturais nessas regiões, nomeadamente, as alterações no emprego, na produção agrícola e os impactos da Reforma Política Agrícola Comum (IRAIZOZ; GORTON; DAVIDOVA, 2007). No entanto não existem estudos específicos que caracterizem e simultaneamente que segmentem as explorações agrícolas dos vinte e oito Estados Membros em grupos de explorações homogêneas à exceção da Rede de Informação de Contabilidades Agrícolas (RICA) cujo propósito é, na sua essência, estritamente econômico.

O objetivo deste trabalho é caracterizar as explorações agrícolas da UE, obtendo para o efeito tipologias robustas de explorações de acordo com critérios de natureza estrutural e financeira. Este trabalho justifica-se de forma a dar orientações aos decisores públicos ao nível da União Europeia (UE) sobre a condução e principalmente sobre a definição de políticas agrícolas para os diferentes Estados Membros (EM) que a compõem.

A tipologia das explorações agrícolas existente atualmente na União Europeia efetua-se através da Rede de Informação de Contabilidades Agrícolas (RICA), que classifica as explorações em função da sua produção, do tamanho da exploração e com base na parcela que cada seção de produção da exploração tem na criação da margem bruta padrão (MBP). A MBP expressa o rendimento econômico de uma unidade de produção para as seções individuais de produção vegetal e animal. $\mathrm{O}$ seu valor corresponde ao valor padrão de produção de 1 ha da cultura ou uma cabeça de uma determinada espécie animal após a dedução dos custos variáveis (específicos) para a sua produção (BAŠEK; KRAUS, 2011). A margem bruta padrão determina assim o ganho econômico de uma unidade de produção vegetal ou animal (DIVILA; SOKOL, 1999). Apesar de tudo, esta tipologia foi definida quando a UE era formada por um diminuto número de países compostos principalmente pelos países da Europa Central. No entanto a adesão posterior dos países mediterrânicos (Portugal, Espanha e Grécia), bem como os Novos Estados Membros da Europa de Leste vieram, pelas suas características estruturais e, principalmente, diferentes 
níveis de produtividade, colocar em causa a homogeneidade das explorações da então Comunidade Econômica Europeia.

$\mathrm{Na}$ UE a apresentação e análise de estatísticas agrícolas têm assim sido associados a uma tipologia comum há várias décadas. No entanto, a lógica por trás desta tipologia agrícola da UE é exclusivamente econômica, porque a tipologia foi decidida em um período em que os principais objetivos das políticas agrícolas estavam relacionados com a produção agrícola (ANDERSON; ELBERSENB; GODESCHALKC; VERHOOGC, 2007). No entanto, atualmente os objetivos da política agrícola foram ampliados mais fortemente no sentido da proteção da paisagem, do meio ambiente e da sustentabilidade rural (DOS SANTOS; HENRIQUES; FRAGOSO; CARVALHO, 2012). Com estas alterações da PAC a tipologia agrícola da UE tem de ser reavaliada como um instrumento para avaliação e acompanhamento de políticas. Este artigo surge nessa perspectiva.

A caracterização das explorações agrícolas dos vinte e oito EM que compõem atualmente a União Europeia (UE) é efetuada através dos dados da RICA de 2010. Os resultados mostram que as explorações da UE apresentam estruturas agrícolas, produtividades e níveis de apoio da PAC diferenciados.

Assim, a superfície agrícola útil (SAU) média dos países da UE é de 78,6 ha. A área mínima é de 3,62 ha, correspondente a Malta, e a área máxima é de 579,35 ha, relacionada à Eslováquia. As grandes explorações agrícolas continuam a predominar nos Novos EM da UE, em particular na Eslováquia (579,3 ha de SAU); a República Checa com 227,8 ha; e Estônia com 131,6 ha de SAU média por exploração. Segundo Bašek e Kraus (2011) isto significa que os processos de restituição, de reestruturação e de privatizações não trouxeram grandes alterações na participação dos privados na posse da terra nestes países. Nos países mediterrâneos a estrutura fundiária é cerca de metade do valor médio da UE, nomeadamente, Espanha (35 ha), isto é, cerca de três vezes inferior, em Portugal (12 ha), ou mesmo 10 vezes inferior à média europeia como sucede na Grécia (7,1 ha).

Relativamente ao indicador SAU/UTA nas explorações agrícolas da UE verifica-se que o Reino Unido ultrapassa em 2,5 vezes a média europeia, o que significa elevados níveis de produtividade da sua agricultura (BAŠEK; KRAUS, 2011). Em segundo e terceiro lugar surgem a Suécia e a Dinamarca com um indicador de 
produtividade indireto de 2,3 e 2 vezes superior à média europeia que é cerca de 28 .

A agricultura europeia é igualmente bastante subsidiada. Em média os subsídios agrícolas emanados da Política Agrícola Comum (PAC) representam cerca de $23 \%$ no conjunto total da produção dos países da UE. Os países que mais contribuem para este valor são a Finlândia, que ultrapassa 2,5 vezes a média europeia, e a Irlanda, cujo valor dos subsídios no conjunto total da produção é cerca do dobro da UE $(43,3)$. Os países menos subsidiados são a Holanda, a Dinamarca e a Romênia, em que os subsídios representam respectivamente 4,1, 10,8 e 10,5 no conjunto dos países europeus.

Assim, face a diferenças estruturais, de competitividade e de níveis de apoio da PAC nos EM da UE, torna-se necessário a sua classificação em grupos homogêneos de forma a poder delinear políticas agrícolas mais consentâneas com a realidade desses países. Segundo Pereira (2015), por meio da pesquisa, consolida-se o conhecimento científico de forma honrada, fruto do trabalho de muitas gerações, como disse Albert Einstein.

\section{MATERIAL E MÉTODOS}

Existe um largo consenso entre os diferentes autores sobre a importância das técnicas de análise multivariada na definição de tipologias de empresas agrícolas através da análise multivariada (DOS SANTOS et al., 2010a). A análise multivariada tem sido a técnica largamente utilizada com sucesso para analisar as trajetórias das explorações agrícolas, nomeadamente, por Campos et al. (2014), que analisaram as trajetórias tecnológicas agropecuárias das microrregiões mineiras entre os anos de 1996 e 2006, identificando-as quanto a tamanho e escala, modernização, tecnologia, produtividade, adoção de práticas de conservação e as relações entre essas dimensões. Para isso, utilizaram a Análise Fatorial Múltipla (AFM) e agrupamentos. De igual forma, Iraizoz et al. (2007) analisaram as trajetórias da região de Navarra, em Espanha, com recurso à análise de cluster, tendo-se baseado na mudança estrutural ocorrida e nas características das explorações agrícolas. Dos Santos et al. (2010a), Silva e Berbel (2007) e Silva; Marta-Costa e Berbel (2015) analisaram as tipologias 
de explorações agrícolas em Portugal através da análise multivariada de clusters. Os dois últimos autores referidos analisaram ainda as tipologias de explorações produtoras de leite nas Ilhas dos Açores, Portugal, tendo utilizado com sucesso, igualmente, a análise de cluster de casos e de variáveis. Desta forma foram assim identificadas cinco clusters de explorações agrícolas.

Assim, para segmentar as explorações da União Europeia e obter grupos de explorações de elevada homogeneidade interna foram igualmente utilizadas no presente trabalho técnicas de análise multivariada, nomeadamente, a análise de cluster de casos e a análise de cluster de explorações. A análise multivariada baseouse nos trabalhos de Dos Santos et al. (2010a); Davidova et al. (2003); Iraizoz et al. (2007); e Costa et al. (2012). Os procedimentos incluíram a análise de cluster de casos e a análise de cluster de variáveis. Esta técnica foi utilizada para formar grupos homogêneos de explorações agrícolas nos vinte e seis EM da UE. Para esse efeito, foi necessário selecionar as variáveis com poder explicativo que permitissem separar as explorações agrícolas dos vinte e seis países, visto não existirem dados disponíveis dos restantes. Tradicionalmente este processo é efetuado com o recurso à análise fatorial de componentes principais, que tem também por finalidade a eliminação da multicolinearidade entre as variáveis. Por se tratar de um número reduzido de observações (inferior a trinta países) utilizamos a análise de cluster de variáveis de acordo com Hair et al. (2005). Esta análise teve por finalidade transformar linearmente um elevado conjunto original de variáveis em um menor número de variáveis não correlacionadas sem perda de informação significativa (HAIR et al., 2005).

Os procedimentos prévios na análise de cluster incluíram a exclusão das variáveis correlacionadas, através da análise de correlação, e a sua posterior standartização através do critério Zscore $=\frac{X_{i}-\bar{X}_{i}}{\sigma}$ em que $X_{i}$ e $\bar{X}_{i}$ e $\sigma$ representam, respectivamente, o valor da variável, a sua média e $\sigma$ o desvio padrão para $i=1,2, \ldots n$

A análise de cluster incluiu como medida de proximidade a distância euclidiana ao quadrado (dij), apresentada na equação (1). Esta medida calcula a distância entre dois pontos como sendo o somatório dos quadrados das diferenças entre os valores $i$ e $j$ para todas as variáveis $(v=1,2 \ldots p)$ (HAIR et al., 2005). 


$$
d i j=\sum_{V=1}^{p}(X i v-X j v)^{2}
$$

O critério de agregação utilizado foi o método de Ward. Este critério consistiu em: a) calcular as médias das variáveis em cada um dos grupos; b) calcular a distância euclidiana ao quadrado entre as médias e os valores das variáveis para cada indivíduo; c) somar as distâncias para todos os indivíduos; e d) otimizar a variância mínima entre os grupos (HAIR et al., 2005).

A análise de cluster de casos foi baseada nos fatores obtidos na análise de cluster de variáveis.

Os dados utilizados provêm da base de dados da RICA e referem-se ao ano de 2010 (FADN, 2013). A análise de dados foi efetuada através do software Statistical Package for Social Sciences (SPSS) versão 19.

\subsection{VARIÁVEIS UTILIZADAS NA ANÁLISE DE CLUSTER}

As variáveis escolhidas para este efeito são aquelas que tradicionalmente têm sido usadas para analisar o desempenho das explorações agrícolas. Para esse efeito foi efetuada a revisão da literatura para ajudar a identificar essas variáveis. As variáveis que foram escolhidas neste estudo para segmentar as explorações agrícolas classificam-se em quatro grupos: variáveis estruturais, uso de fatores de produção, tecnológicas (intensificação) e financeiras.

\subsubsection{A estrutura das explorações agrícolas}

O tamanho da exploração é um fator a ter em consideração, devido à sua importância nas teorias de mudança estrutural que destacam a existência de economias de escala que podem motivar os padrões de crescimento, como evidenciado no trabalho empírico por Paul e Nehring (2005). Argilés (2001); Davidova et al. (2003); Iraizoz et al. (2007); e Fava-Neves et al. (2011) utilizam mais de uma medida para a dimensão da propriedade. Assim, neste trabalho, a dimensão da exploração é representada por quatro variáveis: a superfície agrícola útil (SAUTOT), a mão de 
obra total (TOTALUTA), o valor da produção total excluindo os subsídios diretos (OUTTOT) e o ativo total (TOTASSET).

\subsubsection{Terra arrendada e contratação de mão de obra}

O uso de fatores externos, tais como a superfície de terras arrendadas e a mão de obra contratada, também foi incluído para construir as tipologias das explorações agrícolas da UE. Segundo Soule et al. (2000), a posse da terra é um fator importante nas decisões dos agricultores, por exemplo, na adoção de práticas de conservação e/ou na alteração da intensidade da produção. Além disso, a percentagem de terras arrendadas (PORREUAA) tem sido utilizada como um indicador da predisposição dos agricultores para aumentar o risco (DASKALOPOULOU; PETROU, 2002). A percentagem de trabalho remunerado (PORPALAB) tem igualmente sido utilizada por alguns investigadores como Daskalopoulou e Petrou (2002); Davidova et al. (2003); e Iraizoz et al. (2007) na criação de tipologias de explorações agrícolas. Por isso estas duas variáveis foram incluídas na análise.

\subsubsection{Especialização da exploração agrícola}

Especialização agrícola foi outra das variáveis consideradas. Villatora e Langemeier (2005) concluíram que as explorações mais especializadas na produção vegetal cresceram a uma taxa de crescimento mais rápida do que as explorações especializadas na pecuária. Esta variável é também incluída nos trabalhos desenvolvidos por Davidova et al. (2003) e Iraizoz et al. (2007). Assim inclui-se a variável percentagem da produção vegetal no valor da produção total (PROCRO) e mede-se o grau de especialização da exploração em culturas arvenses.

\subsubsection{Intensificação}

Os fatores de intensificação foram incluídos neste trabalho de acordo com Davidova et al. (2003) e Iraizoz et al. (2007). Assim inclui-se a intensidade de capital que foi medido através da depreciação de capital por unidade de trabalho anual 
(DEPAWU). Além disso incluiu-se ainda a intensificação do fator terra, medida através da SAU por unidade de trabalho anual (SAU/UTA). Valores mais elevados significam baixos níveis de intensificação.

\subsubsection{Componente financeira}

$\mathrm{Na}$ componente financeira as variáveis incluídas foram o cash-flow (CASHFLOW), seguindo a metodologia da RICA e a leverage (Receitas-custos variáveis)/ (receitas-custos variáveis-custos fixos) que seguiu a metodologia desenvolvida por Davidova et al. (2003) e Iraizoz et al. (2007). Para além disso incluiu-se ainda, de acordo com os mesmos autores, a variável rendas pagas/output total (RENGO). Por considerarmos que o grau de dependência das explorações relativamente aos subsídios também eram aspectos importantes que permitem distinguir as explorações da EU foram incluídas as variáveis total dos subsídios (SUBNET) e percentagem dos subsídios no total da produção (SUBOUTP).

\section{RESULTADOS E DISCUSSÃO}

A Tabela 1 apresenta os resultados da matriz de correlação, tendo sido utilizado o coeficiente de correlação de Pearson, com base nos resultados foram excluídas as variáveis que se encontravam correlacionadas.

Tabela 1. Matriz de Correlação com as variáveis selecionadas

(continua)

\begin{tabular}{c|c|c|c|c|c|c|c|c|c|c|c|c}
\hline & \multicolumn{10}{c}{ Variáveis } \\
\hline & $\mathbf{1}$ & $\mathbf{2}$ & $\mathbf{3}$ & $\mathbf{4}$ & $\mathbf{5}$ & $\mathbf{6}$ & $\mathbf{7}$ & $\mathbf{8}$ & $\mathbf{9}$ & $\mathbf{1 0}$ & $\mathbf{1 1}$ & $\mathbf{1 2}$ \\
\hline $\mathbf{1}$ & 1 &, 186 &, 318 &, 42 &,- 150 &, 0712 &, 248 &,- 104 &,- 0528 &, 0559 &, 313 &, 183 \\
\hline $\mathbf{2}$ &, 186 & 1 &, 095 &, 089 &, 054 &, 0704 &, 0739 &, 184 &, 206 &, 087 &, 090 &, 097 \\
\hline $\mathbf{3}$ &, 318 &, 0951 & 1 &, 0951 &, 109 &, 0739 &, 0733 &, 070 &, 083 &, 377 &, 175 &, 132 \\
\hline $\mathbf{4}$ &, 042 &, 0892 &, 0951 & 1 &, 216 &, 0789 &, 065 &, 086 &,- 072 &, 42 &, 230 &, 139 \\
\hline $\mathbf{5}$ &,- 150 &, 054 &, 109 &, 216 & 1 &,- 255 &,- 235 &,- 211 &,- 242 &, 150 &,- 193 &,- 194 \\
\hline
\end{tabular}


(conclusão)

\begin{tabular}{c|c|c|c|c|c|c|c|c|c|c|c|c}
\hline & \multicolumn{10}{c}{ Variáveis } \\
\hline & $\mathbf{1}$ & $\mathbf{2}$ & $\mathbf{3}$ & $\mathbf{4}$ & $\mathbf{5}$ & $\mathbf{6}$ & $\mathbf{7}$ & $\mathbf{8}$ & $\mathbf{9}$ & $\mathbf{1 0}$ & $\mathbf{1 1}$ & $\mathbf{1 2}$ \\
\hline $\mathbf{6}$ &, 0712 &, 0704 &, 0739 &, 0789 &,- 255 & 1 &, 0683 &, 219 &,- 094 &, 368 &, 0495 &, 177 \\
\hline $\mathbf{7}$ &, 248 &, 0739 &, 0733 &, 0653 &,- 235 &, 068 & 1 &, 346 &, 327 &, 227 &, 0461 &, 195 \\
\hline $\mathbf{8}$ &,- 104 &, 184 &, 070 &, 086 &,- 211 &, 219 &, 346 & 1 &, 276 &,- 239 &, 271 &, 095 \\
\hline $\mathbf{9}$ &,- 0528 &, 206 &, 083 &,- 072 &,- 242 &,- 094 &, 327 &, 276 & 1 &,- 0395 &,- 110 &,- 039 \\
\hline $\mathbf{1 0}$ &, 0559 &, 087 &, 377 &, 0426 &, 150 &, 368 &, 227 &,- 239 &,- 0395 & 1 &, 045 &, 240 \\
\hline $\mathbf{1 1}$ &, 313 &, 090 &, 175 &, 230 &,- 193 &, 0495 &, 0461 &, 271 &,- 110 &, 0455 & 1 &, 262 \\
\hline $\mathbf{1 2}$ &, 183 &, 097 &, 132 &, 139 &,- 194 &, 177 &, 195 &, 095 &,- 039 &, 240 &, 262 & 1 \\
\hline
\end{tabular}

Fonte: Elaboração própria.

Os resultados da análise de cluster de variáveis apresentados na Tabela 2 mostraram que as explorações da UE se distinguem entre si por três fatores principais: i) pelas suas características estruturais, nomeadamente, pela sua SAU (SAUTOT), pelo output total (OUTTOT), pela percentagem de trabalho contratado (OUTUTA) e mão de obra total (TOTALUTA); ii) pelas suas características financeiras, isto é, pelo seu ativo total (TOTASSET) e pelo cash-flow das empresas da UE; e iii) pela sua orientação produtiva e importância dos subsídios na exploração. Assim este fator inclui as variáveis percentagem de culturas arvenses na exploração (PROCRO) e percentagem dos subsídios no total da produção (SUBOUTP).

Tabela 2. Principais características dos quatro clusters

(continua)

\begin{tabular}{lcccc}
\hline \multicolumn{5}{c}{ Principais características dos quatro clusters } \\
\hline & \multicolumn{4}{c}{ Cluster } \\
\cline { 2 - 5 } Variável & I & II & III & IV \\
\hline & 50,54 & 38,46 & 403,61 & 79,57 \\
\hline SAUTOT & $2.221,7$ & $1.041,5$ & $1.026,3$ & $2.912,9$ \\
OUTPUT/SAU & 1,7 & 1,84 & 12,0 & 1,86 \\
TOTALUTA & 21,7 & 29,5 & 86,9 & 31,8 \\
OUTUTA(\%) trabalho contratado & & & & \\
& & & & \\
\end{tabular}


(conclusão)

Principais características dos quatro clusters

\begin{tabular}{lcccc}
\hline \multirow{2}{*}{ Variável } & \multicolumn{4}{c}{ Cluster } \\
\cline { 2 - 5 } & I & II & III & IV \\
\hline SAU/UTA & 28,9 & 18,8 & 32,7 & 44,5 \\
DEPAWU (depreciação/UTA) & $8.807,0$ & $6.301,5$ & $9.238,1$ & $7.221,3$ \\
\hline & \multicolumn{5}{c}{ Características Financeiras } \\
\hline TOTASSET activo & $334.166,8$ & $120.129,7$ & $632.311,5$ & $1.030 .662,6$ \\
CASH-FLOW & 22.642 & $10.181,5$ & $2.056,5$ & 37.328 \\
LEVERAGE (MB/MB-depreciação) & 0,79 & 0,81 & 0,76 & 0,76 \\
RENGO (rendas/output total) & 0,040 & 0,026 & 0,032 & 0,039 \\
\hline & \multicolumn{5}{c}{ Orientação Produtiva } \\
\hline PROCRO (\% culturas arvenses) & 44,4 & 55,2 & 56,1 & 33,8 \\
SUBOUTP Subsídios totais/Output & 24,3 & 22,1 & 26,7 & 20,6 \\
\hline
\end{tabular}

Fonte: Elaboração própria.

Com base nestes resultados da Tabela 2 efetuou-se a análise de cluster de casos cujos resultados apresentados no Quadro 1 e na árvore hierárquica permitiram obter quatro clusters que incluem, respectivamente, os seguintes países da UE. O cluster I inclui principalmente os países da Europa Central e do Norte. O cluster II inclui principalmente os países mediterrâneos e alguns países da Europa de Leste. Saliente-se que Itália não aparece nos resultados, por não existirem dados publicados na base de dados da RICA sobre este país. O cluster III inclui parcialmente países da Europa de Leste. Finalmente, o cluster IV inclui o Reino Unido, Luxemburgo, a Dinamarca, a Holanda e a Irlanda.

Quadro 1. Representação dos clusters e países respectivos

(continua)

\begin{tabular}{|l|l|}
\hline \multicolumn{2}{|c|}{ Representação dos clusters e países respectivos } \\
\hline Cluster & \multicolumn{1}{c|}{ Países } \\
\hline I & Alemanha, Áustria, Bélgica, Chipre, Finlândia, França, Lituânia, Malta e Suécia \\
\hline II & $\begin{array}{l}\text { Bulgária, Espanha, Estônia, Eslovênia, Grécia, Hungria, Letônia, Polônia, Portugal e } \\
\text { Romênia }\end{array}$ \\
\hline
\end{tabular}


(conclusão)

\begin{tabular}{|l|l|}
\hline III & Eslováquia, República Checa \\
\hline IV & Dinamarca, Holanda, Irlanda, Luxemburgo e Reino Unido \\
\hline
\end{tabular}
Fonte: Elaboração própria.

Esta análise teve por base a análise de cluster de casos cuja árvore hierárquica se apresenta.

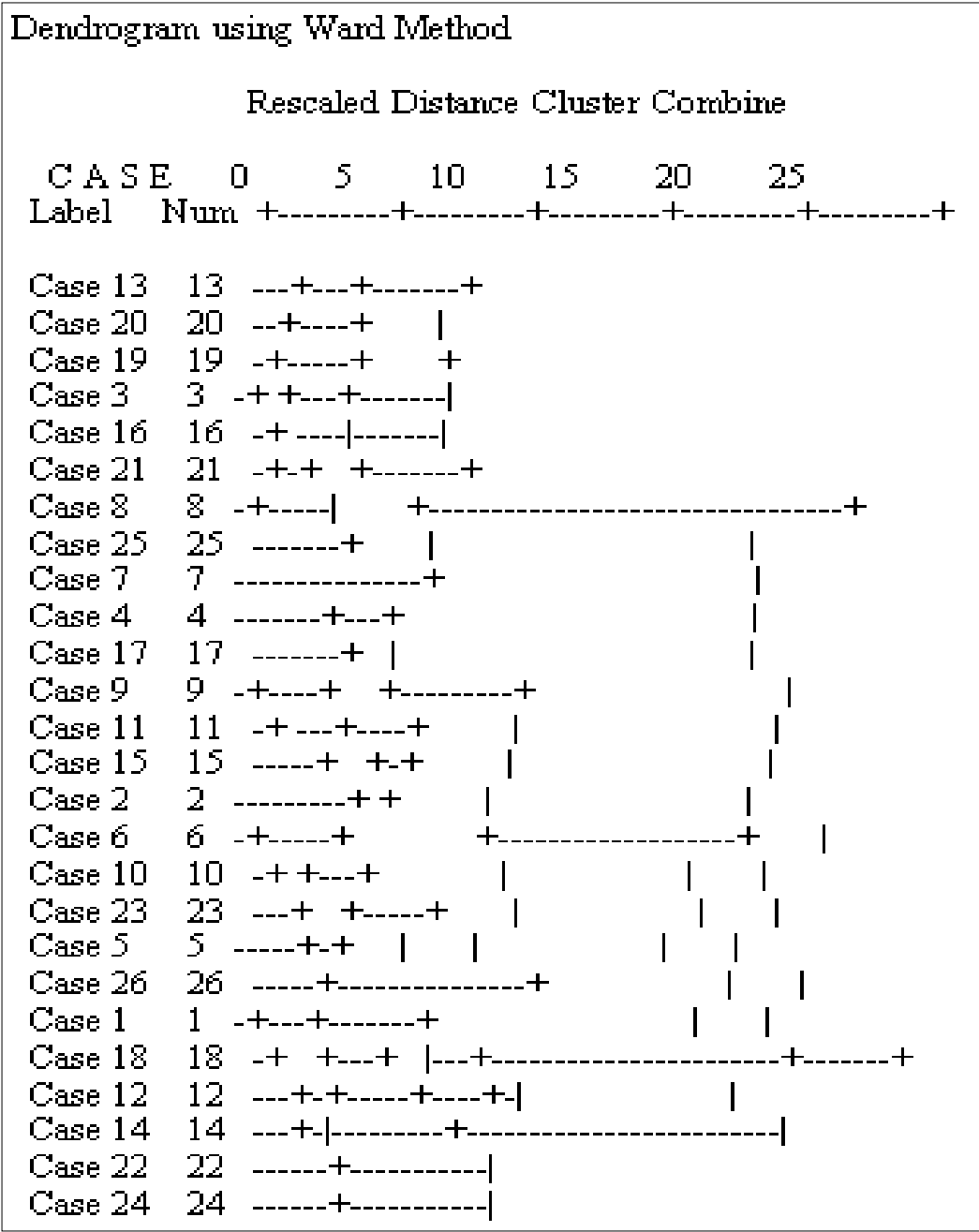

Figura 1. Dendrograma efetuado com base na árvore hierárquica Fonte: Elaboração própria. 
Apresenta-se a análise respectiva dos quatro clusters:

\section{- Cluster I}

Este cluster representa cerca de $36 \%$ dos países da UE. É formado principalmente por países da Europa do Norte cuja área média das suas explorações é de 50 ha, cujo output/SAU é de 2.221 euros/ha, o que representa o segundo valor mais elevado dos quatro clusters existentes. As explorações agrícolas deste grupo possuem em média cerca de 1,7 UTAS das quais apenas cerca de 22\% representam trabalho contratado. A SAU/UTA nestas explorações é de 28,9 ha/UTA, o que perfaz o segundo valor mais elevado dos grupos de explorações da UE. Estas explorações possuem elevados valores de capital por trabalhador (8.807,0 euros), medida através da depreciação de capital por unidade de trabalho anual, o que significa que existe maior intensidade de capital por trabalhador nestas empresas.

No que diz respeito às suas características financeiras estas explorações possuem um ativo total de 334.166,8 euros, o que perfaz apenas 32\% do valor das explorações do cluster IV. O valor do cash-flow é cerca de 22.642 euros, valor que perfaz cerca de $60 \%$ do valor nas explorações do cluster IV.

\section{- Cluster II}

Este cluster representa cerca de $40 \%$ dos países da UE. É formado principalmente por países da Europa do Leste e por países mediterrâneos cuja área média das suas explorações é de aproximadamente 38 ha, cujo output/SAU é de $1.041,5$ euros/ha, o que representa o segundo valor mais baixo dos quatro clusters existentes, perfazendo cerca de 35\% do valor das explorações do cluster IV. As explorações agrícolas deste grupo possuem em média cerca de 1,84 UTAS das quais apenas cerca de $30 \%$ representa trabalho contratado. A SAU/UTA nestas explorações é de 18,8 ha/UTA, o que perfaz o valor mais baixo dos grupos de explorações da UE, representando cerca de um terço do valor das explorações agrícolas do cluster IV. Este resultado indicia elevada intensidade de utilização do fator trabalho. Estas explorações possuem igualmente baixos valores de capital por trabalhador $(6.301,5$ 
euros), o que representa o valor mais baixo dos países da UE, o que significa que existe menor intensidade de capital por trabalhador nestas empresas.

No que diz respeito às suas características financeiras estas explorações possuem um ativo total de 120.129,7 euros, valor que perfaz cerca de 35\%, 18\% e $11 \%$, respetivamente, das explorações dos clusters I, III e IV. O valor do cash-flow é cerca de $10.181,5$ euros, valor que perfaz cerca de $45 \%$, cerca de cinco vezes e um quarto, as explorações do cluster I, III e IV, respectivamente.

- Cluster III

Este cluster representa cerca de $8 \%$ dos países da UE, sendo formado pela Eslováquia e pela República Checa. A área média das suas explorações é de 403,61 ha, cujo output/SAU é de 1.026,3 euros/ha, o que representa o valor mais baixo dos quatro clusters existentes, perfazendo cerca de 35\% do valor das explorações do cluster IV. As explorações agrícolas deste grupo possuem em média cerca de 12 UTAS das quais apenas cerca de $87 \%$ representam trabalho contratado. Estas explorações são as mais intensivas da UE na utilização do fator trabalho ultrapassando cerca de 7, 6 e 6,4 vezes as explorações dos clusters I, II e IV. A SAU/UTA nestas explorações é de 32,7 ha/UTA, o que perfaz cerca de 1,1, 1,7 e 0,73\% o valor das explorações dos clusters I, II e IV, respectivamente. Estas explorações possuem igualmente elevados valores de capital por trabalhador, $(9.238,1$ euros), o que representa o valor mais elevado dos países da UE, o que significa que existe maior intensidade de capital por trabalhador nestas empresas.

No que diz respeito às suas características financeiras estas explorações possuem um ativo total de 632.311,5 euros, valor que perfaz cerca de 1,8, 5,2 e 0,61\%, respectivamente, das explorações dos clusters I, II e IV. O valor do cash-flow é cerca de 2.056,5 euros, valor que perfaz cerca de 9\%, 20\% e 5\% das explorações do cluster I, II e IV, respectivamente. Estas explorações são, conjuntamente com as explorações do cluster II, aquelas que apresentam maior especialização na produção vegetal, nomeadamente nas culturas arvenses que representam cerca de 55\% e 56\%, respectivamente. 
- Cluster IV

Este cluster representa cerca de $12 \%$ dos países da UE, sendo formado pela Dinamarca, Irlanda, Luxemburgo, Holanda e Reino Unido. A área média das suas explorações é de 79,5 ha, cujo output/SAU é de 2.912,9 euros/ha, o que representa o valor mais elevado dos quatro clusters existentes, perfazendo cerca de 1,3 e 12,8, respectivamente, as explorações do cluster I, II e III. As explorações agrícolas deste grupo possuem em média cerca de 1,86 UTAS das quais apenas cerca de 31,8\% representam trabalho contratado. A SAU/UTA nestas explorações é de 44,5 ha/ UTA, o que representa o valor mais elevado dos grupos de explorações europeias indiciando os mais baixos níveis de utilização da mão de obra por hectare. Estas explorações possuem igualmente valores moderados de capital por trabalhador, (7.221,3 euros). Este valor representa cerca de $80 \%$, uma unidade e uma décima e 0,78\%, respectivamente, das explorações dos clusters I, II e III.

No que diz respeito às suas características financeiras estas explorações possuem um ativo total de 1.030.662,6 euros, valor que perfaz cerca de 3, 8,5 e 1,6 vezes respectivamente as explorações dos clusters I, II e III. O valor do cash-flow é cerca de 37.328 euros, valor que perfaz cerca de 1,6, 3,6 e 18 vezes as explorações do cluster I, II e III, respectivamente. Estas explorações são, conjuntamente, as que apresentam menor especialização na produção vegetal, nomeadamente nas culturas arvenses que representam cerca de 33,8\% no total da produção agrícola.

\section{CONSIDERAÇÕES FINAIS}

Conclui-se que as explorações agrícolas dos países da UE se dividem, genericamente, em quatro grandes grupos que se distinguem entre si por três fatores principais: pelas suas características estruturais, pelas suas características financeiras e pela sua orientação produtiva e importância dos subsídios nas explorações.

Os quatro clusters de explorações formados indicam que as explorações da UE se dividem genericamente em explorações dos países do Norte e Centro da Europa, do Mediterrâneo e do Leste. Esta classificação poderá permitir a definição 
de políticas agrícolas mais ajustadas para estas regiões. Poderá também constituir uma metodologia de estudo de tipificação das explorações agrícolas de países da América do Sul. Poderá igualmente servir para formar tipologias de explorações em diferentes regiões do Brasil. Contudo, são necessários estudos mais aprofundados, baseados em dados regionais, que permitam uma classificação mais detalhada, de forma a seccionar não apenas países, mas também regiões europeias homogêneas.

\section{AGRADECIMENTOS}

A autora agradece a todos os revisores anônimos pelo enorme esforço por todas as correções e sugestões de melhoria sugeridas no presente trabalho, que permitiram melhorar substancialmente o mesmo.

\section{REFERÊNCIAS}

ANDERSEN, E.; ELBERSENB, B.; GODESCHALKC, F.; DAVID, V. Farm management indicators and farm typologies as a basis for assessments in a changing policy environment Journal of Environmental Management, v. 82, p. 353-362, 2007.

ARGILÉS, J. M.; SLOF, J. The use of financial accounting information and firm performance: an empirical quantification for farms. Accounting and Business Research, v. 33, n. 4, p. 251-273, 2003.

BASEK, V.; KRAUS, J. Comparison of selected indicators of farms in the EU member states. Agricultural Economics - Czech, v. 57, p. 71-84. 2011.

CAMPOS, S. A. C.; PEREIRA, M. W. G.; TEIXEIRA, E. C. Trajetória de modernização da agropecuária mineira no período de 1996 a 2006. Economia Aplicada, v. 18, n. 4, p. 717-739, 2014.

COSTA, C. C. de M.; REIS, P. R. C.; FERREIRA, M. A. M.; MOREIRA, N. C. Modernização Agropecuária e Desempenho Relativo a Estados Brasileiros. Agroalimentaria. v. 18, n. 34, p. 43-56. 2012. 
DAMIANOS, D.; SKURAS, D. Farm Business and the Development of Alternative Farm Enterprises: an Empirical Analysis in Greece. Journal of Rural Studies, v. 12, p. 273-283. 1996.

DASKALOPOULOU, Irene; PETROU, Anastasia. Utilizing a farm typology to identify potential adopters of alternative farming activities in Greek agriculture. Journal of Rural Studies, v. 18, p. 95-103. 2002.

DAVIDOVA, S.; GORTON, M.; IRAIZOZ, B.; RATINGER, T. Variations in Farm Performance in Transitional Economies: Evidence from the Czech Republic. Journal of Agricultural Economics, v. 53, p. 173-361. 2003.

DIVILA, E.; SOKOL, Z. Problémy klasifikace a třídění zemědělských podniků. Agricultural Economics - Czech, v. 45, p. 459-466. 1999.

DOS-SANTOS, M. J. P. L.; HENRIQUES, P. D. S.; FRAGOSO, R. M. S.; CARVALHO; M. L. S. Attitudes from Portuguese farmers to Common Agricultural Policy. Agricultural Economics - Czech, v. 5, p. 460-469. 2010a.

DOS-SANTOS, M. J. P. L.; FRAGOSO, R. M. S.; HENRIQUES, P. D. S.; CARVALHO, M. L. S. The agricultural competitiveness in Alqueva Portuguese irrigation project under the 2003 CAP Reform and the Health Check. New Medit - Mediterranean Journal of Economics, Agriculture and Environment, v. 9, p. 11-18. 2010b.

EUROPEAN COMMISSION FOR AGRICULTURE AND RURAL DEVELOPMENT. Farm Accountancy Data Network (FADN) database. Disponível em: < http://ec.europa.eu/ agriculture/ricaprod/> . Acesso em: 25 jan. 2013.

FAVA-NEVES, M.; TROMBIN, V. G.; CONSOLI, M. A.; JULCA-BRICENO, B. Manuel; NOGUEIRA, A. J. G. Análisis del Sector Sucroenergético Brasileno bajo un enfoque de planificación estratégica. Agroalimentaria. v. 17, n. 32, p. 29-45. 2011.

HAIR, J. F.; BLACK, W. C.; BABIN, B.; ANDERSON, R. E. Multivariate data analysis. 7. ed. London: Pearson Education, 2010. 
IRAIZOZ, B.; GORTON, M.; DAVIDOVA, S. Segmenting farms for analyzing agricultural trajectories: a case study of the Navarra region in Spain. Agricultural Systems. v. 93, p. $143-169.2007$.

KOBRICH, C.; REHMAN, T.; KHAN, M. Typification of farming systems for constructing representative farming models: two illustrations of the application of multi-variate analyses in Chile and Pakistan. Agricultural Systems, v. 76, p. 141-157. 2003.

PAUL, C. J. M.; NEHRING, R. Product diversification, production systems, and economic performance in U.S. agricultural production. Journal of Econometrics, v. 126, p. 525-548. 2005.

PEREIRA, M. T. Editorial. Revista em Agronegócio e Meio Ambiente v. 8, n. 3, 2015.

PODRUZSKI, S.; HUBBARD, C.; KESZTHEL, S. Farm income variability in Hungary: a comparison with the EU based on FADN records. In: MEMORIAS DEL SEMINAR INCOME STABILIZATION IN A CHANGING AGRICULTURAL WORLD: POLICIES AND TOOLS, 2008. Anais... Warsaw: European Agricultural Economic Seminar, 2008. p. 30-46.

SANTOS, M. J. P. L.; HENRIQUES, P. D. S.; FRAGOSO, R. M. S.; CARVALHO, M. L. S. A competitividade do regadio de Alqueva: o caso do bloco de rega do Monte Novo, Revista de Economia e Sociologia Rural, v. 50, n. 1, p. 107-118. 2012.

SILVA, E.; BERBEL, J. An Azorean farms typology. New Medit - Mediterranean Journal of Economics, Agriculture and Environment, v. 6, p. 51-54. 2007.

SILVA, E.; MARTA-COSTA, A. A.; BERBEL, J. The Objectives and Priorities for the Azorean Dairy Farmers' Decisions. In: THE AGRICULTURAL Economics of the 21st Century, ed. Vítor João Pereira Domingues Martinho, p. 137-156. Springer International Publishing. 2015.

SOULE, M.; TEGENE, A.; WIEBE, K. D. Land Tenure and the Adoption of Conservation Practices. American Journal of Agricultural Economics, v. 82, n. 4, p. 993-1005, 
2000.

VILLATORA, M.; LANGEMEIER, M. Factors impacting farm growth. In: ANNUAL MEETING SOUTHERN AGRICULTURAL ECONOMICS ASSOCIATION, 2005, Anais... Arkansas: Agricultural Economic Association, 2005. p. 120-135.

Recebido em: 23 de março de 2014 Aceito em: 21 de fevereiro de 2016 